\title{
Extracellular Heat Shock Protein 70: A Critical Component for Motoneuron Survival
}

\author{
Mac B. Robinson, ${ }^{\star}$ J. Lille Tidwell, ${ }^{\star}$ Thomas Gould, Anna R. Taylor, Jason M. Newbern, Jason Graves, Michael Tytell, \\ and Carol E. Milligan \\ Department of Neurobiology and Anatomy, Wake Forest University School of Medicine, Winston-Salem, North Carolina 27157
}

The dependence of developing spinal motoneuron survival on a soluble factor(s) from their target, muscle tissue is well established both in vivo and in vitro. Considering this apparent dependence, we examined whether a specific component of the stress response mediates motoneuron survival in trophic factor-deprived environments. We demonstrate that, although endogenous expression of heat shock protein 70 (HSP70) did not change during trophic factor deprivation, application of e-rhHsp70 (exogenous recombinant human Hsp70) promoted motoneuron survival. Conversely, depletion of HSP70 from chick muscle extract (MEx) potently reduces the survivalpromoting activity of MEx. Additionally, exogenous treatment with or spinal cord overexpression of Hsp70 enhances motoneuron survival in vivo during the period of naturally occurring cell death [programmed cell death (PCD)]. Hindlimb muscle cells and lumbar spinal astrocytes readily secrete HSP70 in vitro, suggesting potential physiological sources of extracellular Hsp70 for motoneurons. However, in contrast to exogenous treatment with or overexpression of Hsp70 in vivo, muscle-targeted injections of this factor in an ex vivo preparation fail to attenuate motoneuron PCD. These data (1) suggest that motoneuron survival requirements may extend beyond classical trophic factors to include HSP70, (2) indicate that the source of this factor is instrumental in determining its trophic function, and (3) may therefore influence therapeutic strategies designed to increase motoneuron Hsp70 signaling during disease or injury.

Key words: muscle extract; cell death; apoptosis; stress response; Hsp70; motoneuron; trophic

\section{Introduction}

Neurotrophic factors are defined by their ability to support the survival of developing and/or mature neurons, and the dependence of motoneurons on target-derived trophic support is well documented (Dohrmann et al., 1986; Oppenheim et al., 1988; Crews and Wigston, 1990; Eagleson et al., 1990). A deficit of trophic factors has been proposed as an underlying cause of neurodegenerative diseases including amyotrophic lateral sclerosis (ALS) (Appel, 1981). Nonetheless, the specific trophic factors and mechanisms by which they promote motoneuron survival are not clear (Henderson, 1996; Oppenheim, 1996). Considering the importance of trophic support for promoting neuronal survival, we hypothesize that its loss should initiate a stress response by the cell. The ability of the neuron to initiate such a response may then influence its survival.

A hallmark of the "stress response" is the upregulation of heat shock proteins (Hsps). The $70 \mathrm{kDa}$ family of Hsps (HSP70) con-

\footnotetext{
Received July 9, 2003; revised Sept. 5, 2005; accepted Sept. 8, 2005.

This work was supported by National Institutes of Health-National Institute of Neurological Disorders and Stroke (NINDS) Grant NS03061 (C.E.M.) and intramural research awards and NINDS Grant NS046615 (C.E.M., M.T.). We thank Siwei Wang for technical assistance and Drs. David Riddle, Ron Oppenheim, and Ashok Hegde for critically reading and discussing a previous version of this manuscript.

*M.B.R. and J.L.T. contributed equally to this work.

Correspondence should be addressed to Dr. Carol E. Milligan, Department of Neurobiology, Wake Forest University School of Medicine, Medical Center Boulevard, Winston-Salem, NC 27157. E-mail: milligan@wfubmc.edu.

J. L. Tidwell's present address: 3100 Wisconsin Avenue NW, \#4, Washington, DC 20016. E-mail: jlt20016@gmail.com.

DOI:10.1523/JNEUROSCI.1912-05.2005

Copyright $\odot 2005$ Society for Neuroscience $\quad$ 0270-6474/05/259735-11\$15.00/0
}

tains a number of related isoforms, including a constitutively expressed form, Hsc70, and an inducible form, Hsp70 (Tavaria et al., 1996; Kiang and Tsokos, 1998; Mallouk et al., 1999). Although there are few structural or functional differences between the two proteins, they differ in transcriptional regulation (Brown et al., 1993; Kiang and Tsokos, 1998). Intracellular HSP70 has several identified functions, including stabilization of protein structures and the prevention of protein aggregation by binding to unfolded proteins and, consequently, regulation of protein activity, availability, and/or transport (Welch and Feramisco, 1985; Lindquist and Craig, 1988; Hartl, 1996).

Although increases in transcription and translation of Hsp70 have been used classically to monitor the stress response in the nervous system, the necessity of this response for cell protection is currently under investigation (Brown, 1991; Sharp et al., 1999; Yenari et al., 1999; Rajdev et al., 2000). Inhibition of Hsp70 or Hsc70 expression has been shown to result in increased vulnerability of the cells to metabolic stress (Nakata et al., 1993; Lasunskaia et al., 1997; Rubio et al., 2002). Although the best understood role of HSP70 relates to its intracellular functions, secretion or release of HSP70 by one cell population to act on neighboring cells has been suggested (Tytell et al., 1986; Hightower and Guidon, 1989; Guzhova et al., 2001). Although it is unclear how extracellular Hsps function, there is evidence that they can be internalized and readily imported into both cytoplasmic and nuclear compartments of many cell types and that they appear to promote survival (Johnson et al., 1990, 1995; Houenou et al., 
1996; Guzhova et al., 1998; Fujihara and Nadler, 1999; Yu et al., 2001; Tidwell et al., 2004).

In this study, we found that motoneurons do not upregulate HSP70 in response to various stressors. We also investigated the potential role of extracellular HSP70 in protection of spinal motoneurons deprived of trophic support in vitro or undergoing naturally occurring cell death in vivo. Our results suggest that e-rhHSP70 is necessary and sufficient to regulate motoneuron survival. Furthermore, the cellular source of the endogenous protein appears to be important in mediating motoneuron survival.

\section{Materials and Methods}

Motoneuron cultures. Motoneurons were isolated from embryonic day 5.5 (E5.5) chick spinal cord as described previously (Milligan et al., 1994). Briefly, spinal cords were dissected, dissociated with trypsin, and centrifuged over a $6.8 \%$ metrizamide gradient. After isolation, cells were plated at a density of 100 cells $/ \mathrm{mm}^{2}$. Cells were $70-80 \%$ pure as determined by immunostaining for islet-1. Muscle extract (MEx) was prepared as a source of trophic support for motoneurons (Oppenheim et al., 1988). Surviving cells were defined by light microscopy as phase-bright cells whose neurite length was at least twice the diameter of the cell body. Cells were counted across two perpendicular diameters of the culture dish. The number of surviving cells was expressed as a percentage of the number of motoneurons detected in positive controls. Statistical significance was evaluated using ANOVA followed by Tukey-Kramer post hoc test.

Muscle cell cultures. Cells from the hindlimb muscle were isolated and cultured from E11 chicks (as described with minor modifications) (Neville et al., 1998). Muscle cells were grown to confluence in serumcontaining growth medium until myotubules were observed and then maintained in serum-free differentiation medium for the duration of the culture.

Astrocyte cultures. Astrocytes were purified from E12 chick lumbar spinal cord and isolated (as described with minor modifications) (Levison and McCarty, 1991). After isolation, spinal cords were subjected to brief trypsin digestion and dissociated cells were grown in T75 tissue culture flasks in serum-containing medium. After 1 week in culture, O2A progenitors, microglia, and residual neurons were removed by shaking overnight in an orbital shaker at $250 \mathrm{rpm}$. Cells were removed with trypsin and differentiated in defined medium containing the G5 supplement (Michler-Stuke et al., 1984) (Invitrogen, San Diego, CA). Cultures were $95 \%$ pure as determined by glial fibrillary acidic protein (GFAP) immunoreactivity.

Luciferase assay. Luciferase refolding assays were performed according to published protocols to confirm the functionality of recombinant Hsp70 protein (Schumacher et al., 1996) (StressGen, Victoria, British Columbia, Canada). Briefly, heat-denatured luciferase was added to rabbit reticulocyte lysate (a kind gift from Dr. David Toft, Department of Biochemistry and Molecular Biology, Mayo Graduate School, Rochester, $\mathrm{MN}$ ), $1.6 \mu \mathrm{g} / \mathrm{ml}$ cochaperone YDJ (also a gift from Dr. David Toft), with or without $1 \mu \mathrm{g} / \mathrm{ml} \mathrm{Hsp} 70$. After incubation for $2 \mathrm{~h}$ at $25^{\circ} \mathrm{C}$, this reaction mixture was added to the luciferin substrate (Steady Glo Assay Buffer; Promega, Madison, WI). Activity was measured on a Turner luminometer and was expressed as a percentage of controls.

Uptake of biotinylated $\mathrm{Hsc70}$. Motoneurons were incubated with 10 $\mu \mathrm{g} / \mathrm{ml}$ exogenous biotin-labeled recombinant bovine Hsc70 or ovalbumin. Cells were rinsed, fixed, permeabilized, and incubated with cyanine 3 (Cy3)-conjugated streptavidin followed by confocal imaging.

Western blot analysis. Western blots were done using standard procedures. Ten to $30 \mu \mathrm{g}$ of cell extracts were collected and resolved on SDSPAGE gels and transferred to polyvinylidene difluoride (PVDF) membrane for blotting. Membranes were blocked and incubated with primary antibodies diluted in 5\% nonfat dry milk prepared in Tris-buffered saline plus $0.1 \%$ Tween 20 followed by incubation with peroxidase-conjugated secondary antibodies. Protein expression was evaluated after reaction of membranes with enhanced chemiluminescence (Pierce, Rockford, IL) and exposure to X-ray film. Density was analyzed using the Kodak (Rochester, NY) digital science 1D software.
Caspase-3 immunocytochemistry and activity assay. Activation of caspase- 3 was evaluated under the indicated conditions using an antibody specific for cleaved caspase-3 (Cell Signaling, Beverly, MA). Immunoreactivity was analyzed by fluorescence microscopy after incubation with a Cy3-conjugated secondary antibody. Positive cells were expressed as a fraction of total cells and compared among conditions using ANOVA followed by the Tukey-Kramer post hoc test. The caspase-3 activity assay was performed using a Quantizyme Assay System (Biomol, Plymouth Meeting, PA).

Treatment of embryos. Fertilized eggs were windowed at E3 and treated at E6 and E7 with either $25 \mu \mathrm{g}$ of e-rhHsp70 (StressGen) diluted in $0.1 \%$ $\mathrm{BSA} /$ saline in a total volume of $100 \mu \mathrm{l}$, or BSA/saline only (control). At E7.5-E8, the peak of developmental motoneuron death, embryos were killed and fixed in 4\% paraformaldehyde at room temperature for $1 \mathrm{~h}$. For experiments to count the number of healthy cells, the lumbar region of the spinal cord was processed for paraffin embedding. Ten micrometer sections were stained with thionin as described previously (Chu-Wang and Oppenheim, 1978). Healthy and pyknotic motoneurons were counted in every 10th section (Clarke and Oppenheim, 1995). For experiments to count pyknotic or caspase-3-immunoreactive cells, the fixed tissue was infiltrated with 30\% sucrose, embedded in 3:2 30\% sucrose/ OCT cryopreservation compound (Tissue-Tek; Miles, Elkhart, IN), and snap-frozen in 2-methylbutane on dry ice. Every 15th section, cut at 10 $\mu \mathrm{m}$ through the lumbar lateral motor column (LMC), was stained with a mouse antibody against Islet-1/2 (1:100; Developmental Studies Hybridoma Bank, Iowa City, IA), a rabbit antibody against activated caspase-3 (1:250; Cell Signaling) and $1 \mu \mathrm{g} / \mathrm{ml}$ Hoechst 33342 (Sigma, St. Louis, $\mathrm{MO}$ ). Dying motoneurons were counted if they were in the LMC (on account of Islet-1/2 immunoreactivity) and displayed a pyknotic profile (Clarke and Oppenheim, 1995). Activated caspase-3-immunoreactive motoneurons were also counted in each section.

In ovo electroporation. Total RNA was extracted from the liver of an adult mouse that had been anesthetized with ketamine/xylazine and placed in a $42^{\circ} \mathrm{C}$ incubated chamber for $45 \mathrm{~min}$. Primers directed against the $5^{\prime}$ and $3^{\prime}$ ends of mouse Hsp70-1 and containing EcoRI and BamH1 restriction sites were used to clone this CDNA in a PCR with PFU Turbo DNA Polymerase (Stratagene, San Diego, CA). The PCR product was digested with EcoRI and BamHI and ligated into the appropriate sites of pMES, an expression vector containing the chick $\beta$-actin/cytomegalovirus (CMV) promoter driving expression of internal ribosomal entry site 2 (IRES2)-green fluorescent protein (GFP). Sequencing confirmed identity and ligation. Electroporations were performed as described (Gould and Oppenheim, 2004). At E8, embryos were killed, scored for successful electroporation under FITC fluorescence using an inverted microscope, fixed, cryoprotected, and cut at $10 \mu \mathrm{m}$. Dying motoneurons were quantified as described in the preceding section, and transgene expression was assessed by performing immunohistochemistry with an antibody against mouse Hsp70 (1:500; StressGen).

Muscle injections. E7.5 chick embryos were killed, eviscerated, and laminectomized in oxygenated Tyrode's solution. The entire hindlimb was injected with either saline or recombinant human Hsp70 (StressGen) at the indicated dose, together with the retrograde tracer Alexa Fluor 594-conjugated cholera toxin- $\beta$ to visualize lumbar motoneurons affected by $\mathrm{Hsp} 70$ treatment. Spinal cord-hindlimb preparations were incubated at $32^{\circ} \mathrm{C}$ for $16 \mathrm{~h}$ in $1 \mathrm{~L}$ of oxygenated Tyrode's solution (medium changed once after $8 \mathrm{~h}$ ). After incubation, spinal columns were fixed for $1 \mathrm{~h}$ with $4 \%$ paraformaldehyde, transferred to $30 \%$ sucrose, and embedded in three parts: two parts $30 \%$ sucrose/OCT. Ten-micrometerthick sections were cut on a cryostat and stained with Hoechst 33342. Labeled pyknotic nuclei were counted in every 10th section of the lumbar lateral motor column (Gould and Oppenheim, 2004).

Detection of HSP70 from conditioned medium. Medium was collected from astrocytes or muscle cells after $3 \mathrm{~d}$ in culture. After removal from cultures, the medium was centrifuged to remove any residual cells. Samples were incubated with ATP-agarose beads (Sigma) and washed, and the proteins were eluted with $3 \mathrm{~mm}$ ATP. Elutents were precipitated with TCA at a final concentration of $15 \%$, and pellets were reconstituted with $1 \times$ Laemmli sample buffer. Samples were neutralized with $0.5 \mathrm{M}$ Tris, $\mathrm{pH}$ 
7.5, and subjected to Western blot analysis with an antibody that recognizes both Hsp70 and Hsc70 (StressGen).

Removal of HSP70 from MEx. HSP70 was removed from MEx through two chromatographic steps, each performed in the presence of PMSF; anion exchange chromatography using DE-52 medium (Whatman, Maidstone, UK) and affinity chromatography using C-8-linked ATP agarose beads (Sigma). MEx was prepared as previously described (Oppenheim et al., 1988). For preparation of MEx for ion exchange chromatography, $1 \mathrm{ml}$ aliquots were dialyzed against buffer A ( $20 \mathrm{~mm}$ Tris acetate, $\mathrm{pH}$ 7.6, $10 \mathrm{~mm} \mathrm{NaCl}, 2 \mathrm{~mm}$ DTT, $0.1 \mathrm{~mm}$ EDTA) overnight at $4^{\circ} \mathrm{C}$. The dialyzed protein solution was loaded onto $40 \mathrm{ml}$ of DE-52 and washed with 5 column volumes of buffer A. Elution of the proteins was performed in a stepwise manner using buffer A with varying salt concentrations of $100,125,150$, and $300 \mathrm{~mm} \mathrm{NaCl}$. The elution fractions from the $100-150 \mathrm{~mm} \mathrm{NaCl}$ washes that contained HSP70 were pooled and dialyzed against buffer $\mathrm{B}$ (base buffer A containing $3 \mathrm{~mm} \mathrm{MgCl}_{2}$ ) overnight at $4^{\circ} \mathrm{C}$. These fractions were then loaded onto $7 \mathrm{ml}$ of C-8-linked ATP agarose and washed with 5 column volumes of buffer B plus $250 \mathrm{~mm}$ $\mathrm{NaCl}$. HSP70 was eluted from the column using buffer B plus 3 mM ATP. To concentrate the remaining proteins for use in culture, all fractions of the chromatography process were pooled except for the ATP affinity column elution fractions. The pooled fractions were dialyzed against PBS multiple times overnight at $4^{\circ} \mathrm{C}$, and then lyophilized. The lyophilized product was brought up in Milli- $\mathrm{Q}_{2} \mathrm{O}$ and dialyzed against PBS overnight at $4^{\circ} \mathrm{C}$. A control sample of MEx was subjected to the same chromatographic steps, but in this case, all of the fractions, including the ATP-eluted fractions, were pooled and concentrated. Western blot analysis and Coomassie staining of extracts were used to determine the amount of HSP70 remaining in the final extract and the protein integrity after the removal process.

\section{Results}

\section{Motoneurons do not upregulate HSP70 when deprived of} trophic factor or exposed to the prototypical heat stress

To examine the stress response of motoneurons, we used an in vitro model of trophic factor deprivation. Motoneurons cultured with soluble skeletal MEx, a potent source of target-derived trophic support, are healthy (demonstrated by phase-bright cell bodies and extensive neurite outgrowth). In contrast, motoneurons cultured without MEx become committed to undergo cell death within $16 \mathrm{~h}$ after plating and most die within 2-3 d (Milligan et al., 1994). Western blot analysis of protein extracts collected from motoneurons over a $24 \mathrm{~h}$ period indicated the presence of both Hsc70 and Hsp70. At no time within this interval was there evidence for the upregulation of these proteins when motoneurons were deprived of trophic support (Fig. 1A,B).

Because Hsc70 or Hsp70 expression in motoneurons did not appear to change in response to trophic factor deprivation, we tested whether expression of these proteins changed after subjecting cultured motoneurons to the prototypical stress, heat shock of $45^{\circ} \mathrm{C}$ for $1 \mathrm{~h}$. No significant change in expression of HSP70, as detected by using an antibody that recognizes both forms, was observed by $4 \mathrm{~h}$ after heat shock (Fig. $1 C$ ). Comparable blots that were probed with an antibody that recognizes only Hsp70 failed to detect any differences in levels of this protein. In contrast, the expression of heat shock proteins 27, 40, and 90 did increase in response to heat stress, despite the absence of an increase in expression of HSP70 (Fig. 1D).

\section{Exogenous application of HSP70 promotes motoneuron survival}

Because motoneurons die after trophic factor deprivation and do not upregulate HSP70, potentially increasing their vulnerability to stress, we tested whether exogenous application of Hsp70 or Hsc70 would promote motoneuron survival in the absence of trophic factors. Motoneurons were cultured with or without
A

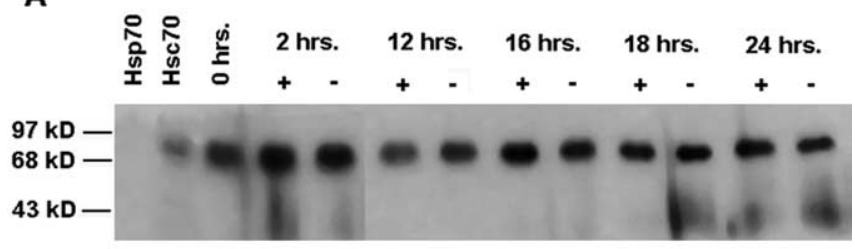

B

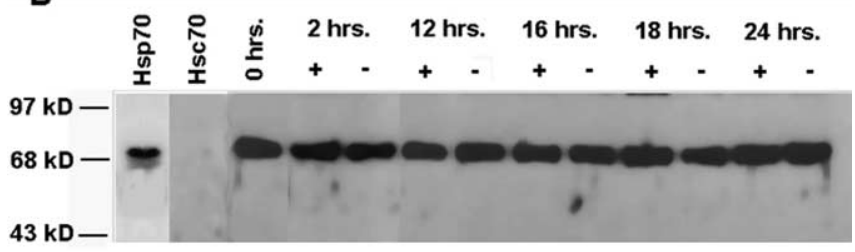

$43 \mathrm{kD}$

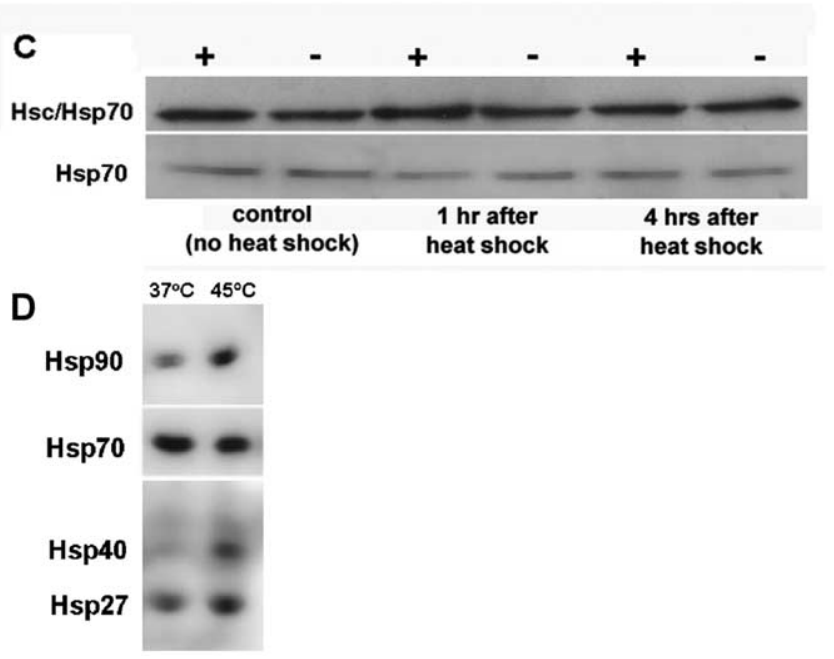

Figure 1. Endogenous expression of $\mathrm{Hsc70}$ and $\mathrm{Hsp} 70$ is not changed in motoneurons cultured with or without trophic support (MEx). $\boldsymbol{A}$ and $\boldsymbol{B}$ are images of representative Western blots from three replicate determinations. Each sample lane was loaded with $10 \mu \mathrm{g}(\boldsymbol{A})$ or $25 \mu \mathrm{g}(\boldsymbol{B})$ of cell lysate protein at the indicated times after plating and probed with anti-Hsc70 and anti$\mathrm{Hsp} 70$, respectively. Levels of Hsc70 were readily detected, whereas detection of Hsp70 required increased exposure of film to the membrane. As such, levels of $\mathrm{Hsp} 70$ are thought to be significantly lower. Mean ratios of samples with and without MEx were calculated at each time by densitometric analysis and compared with the value of 1 . No significant changes were found (as determined by ANOVA), indicating no difference in expression of $\mathrm{Hsc70}$ or $\mathrm{Hsp} 70$ between conditions at any time point examined (data not shown). C, Motoneurons cultured with or without MEx for $24 \mathrm{~h}$ were subjected to heat stress at $45^{\circ} \mathrm{C}$ for $1 \mathrm{~h}$. Protein extracts were collected 1 and $4 \mathrm{~h}$ later. Neither Hsc70 nor Hsp70 levels appeared to change. D, Heat shock of motoneurons for $1 \mathrm{~h}$ at $45^{\circ} \mathrm{C}$ resulted in increased expression of Hsp27, -40 , and -90 , but not -70 .

MEx, or without MEx and with exogenous recombinant human Hsp70 (e-rhHsp70), exogenous recombinant bovine constitutive Hsc70 (e-rbHsc70), or ovalbumin. The addition of e-rhHsp70 or e-rbHsc70 significantly increased motoneuron survival in cultures lacking MEx (Fig. 2A-D). Concentrations of Hsc70 or Hsp70 that promoted significant motoneuron survival ( $1 \mu \mathrm{M}$ or $75 \mu \mathrm{g} / \mathrm{ml}$ ) are lower than those reported to be active in the stress response (Nollen and Morimoto, 2002). Administration of ovalbumin, a protein of similar size to Hsp70, had no survival-promoting activity (Fig. 2D). Interestingly, when e-rhHsp70 $(75 \mu \mathrm{g} / \mathrm{ml})$ is added to cultures treated with MEx, survival is substantially enhanced compared with cultures with MEx alone (Fig. $2 H$ ).

To confirm the interaction of the added protein with motoneurons, biotin-labeled Hsc70 was used. Streptavidin revealed Hsc70 on the cell membrane and, to some extent, in the cytoplasm of the motoneurons (Fig. 2E-G). 
Luciferase refolding assays were conducted to confirm that the recombinant proteins were functional. In this assay, the protein luciferase is heat-denatured, and then its ability to interact with its substrate luciferin is determined by measuring the generation of light. Both Hsp70 and Hsc70 provided the expected $30-50 \%$ recovery of activity, suggesting that both recombinant proteins were functional in terms of traditional HSP70 protein-refolding abilities (Schumacher et al., 1996) (data not shown). Because of the interspecies structural conservation of HSP70, the similarities of the amino acid sequences of Hsp70 and $\mathrm{Hsc70}$, and their comparable survivalpromoting activity in vitro, only e-rhHsp70 was used in subsequent experiments.

To determine whether survivalpromoting activity is unique to exogenous Hsp70 or a common feature of all heat shock proteins, we added recombinant Hsp27, -40, and -90 to motoneurons cultured in the absence of MEx. The addition of exogenous Hsp27 and -40 did not promote motoneuron survival in the absence of trophic support; however, addition of Hsp90 promoted motoneuron survival comparable with that seen with addition of Hsp70 (Fig. $2 \mathrm{H}$ ).

\section{Caspase- 3 activation is reduced when motoneurons are treated with exogenous Hsp70}

Hsp70 upregulation correlates with improved survival of stressed cells, but the mechanism of action remains unclear (Latchman, 1995; Punyiczki and Fesus, 1998; Samali and Orrenius, 1998; Vayssier and Polla, 1998). Caspase- 3 activation is one of the intracellular events mediating spinal motoneuron death after trophic factor deprivation in vitro and during naturally occurring motoneuron death in vivo (Li et al., 1998, 2001). Induced expression or overexpression of Hsp70 inhibits poly(ADP-ribose) polymerase cleavage, suggesting that Hsp70 may inhibit caspase activation (Gabai et al., 1997; Mosser et al., 1997; Buzzard et al., 1998). Therefore, we tested whether e-rhHsp70 inhibits caspase-3 activation in motoneurons. Immunocytochemistry revealed activated caspase- 3 in the cytoplasm of motoneurons cultured without trophic support at $24 \mathrm{~h}$, whereas motoneurons cultured either with MEx, or without MEx but treated with $75 \mu \mathrm{g} / \mathrm{ml} \mathrm{e-rhHsp70}$ showed significantly reduced activated caspase-3 (Fig. $3 A-G$ ). To determine whether e-rhHsp70 directly inhibited caspase activity, we added the protein to an in vitro assay for caspase- 3 activity. There was no direct inhibition of caspase-3-like activity by Hsp70 (Fig. $3 H$ ). These results indicate that application of extracellular Hsp70 does not promote survival by directly inhibiting caspase-3-like activity but rather acts upstream of caspase- 3 activation.

We showed previously that motoneurons deprived of MEx are committed to death $\sim 16 \mathrm{~h}$ after plating (Milligan et al., 1994).
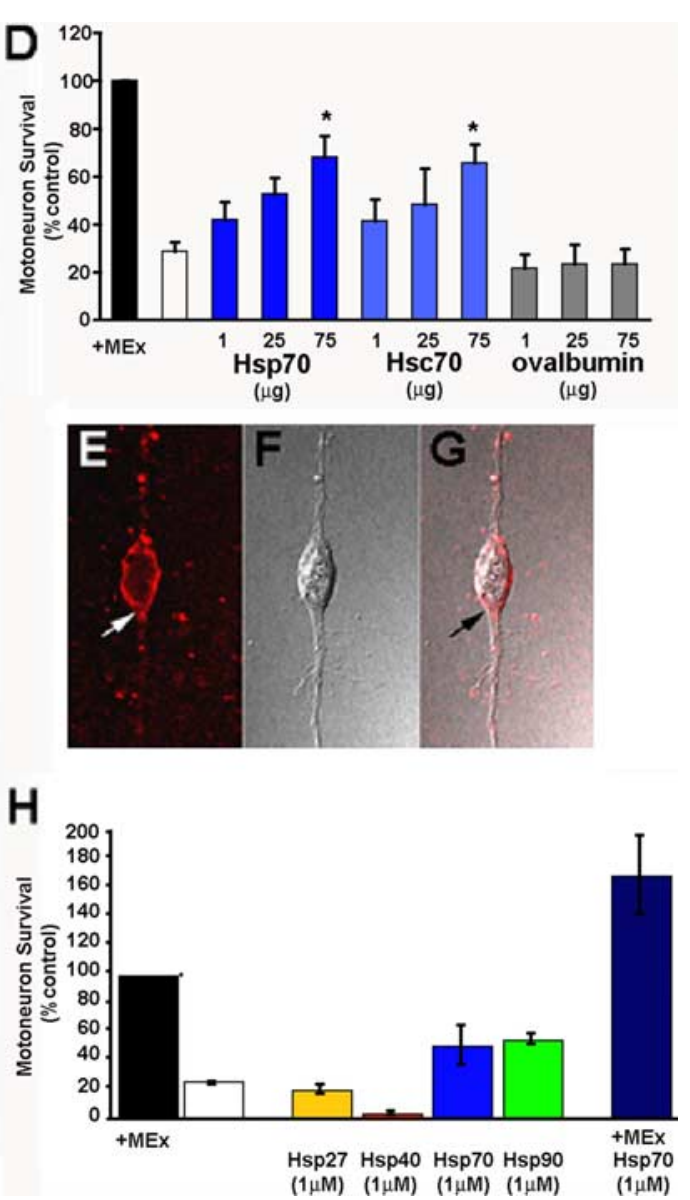

Figure 2. Exogenous $\mathrm{Hsp70}$ and $\mathrm{Hsc70}$ promote motoneuron survival. Representative phase-contrast photomicrographs of motoneurons are shown after $3 \mathrm{~d}$ in culture plated in the absence of trophic support but with addition of rhHsp70 $(75 \mu \mathrm{g} / \mathrm{ml} ; \boldsymbol{A})$, $\operatorname{MEx}(\boldsymbol{B})$, or neither $(\boldsymbol{C})$. Cultures contained healthy cells as indicated by round phase-bright cell bodies with extensive neurite

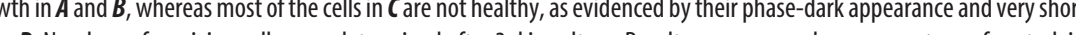
cultured motoneurons. Confocal, fluorescent $(\boldsymbol{E})$, differential interference contrast $(\boldsymbol{F})$, and overlay $(\boldsymbol{G})$ images are presented of a Control cultures with no protein added showed no fluorescent staining (data not shown). $\boldsymbol{H}$, Numbers of surviving cells were determined after $3 \mathrm{~d}$ in culture after addition of Hsp27, -40,-70, or -90 (1 $\mu \mathrm{m})$, or Hsp70 (1 $\mu \mathrm{m})$ plus MEx. Results are expressed as a percentage of control, in which control represents cultures supplied with MEx (average $\pm S D ; n=2$ independent experiments with 3-4 wells per condition per experiment).

Events associated with this death include translocation of Bax from the cytoplasm to organelle membranes, release of cytochrome $c$ from mitochondria to the cytoplasm, activation of caspase-9, -1, and -3, and cleavage of APP (amyloid precursor protein) by caspase-3 (Milligan et al., 1994, 1995; Barnes et al., 1998; Li et al., 1998, 2001; Sato et al., 1998). To determine whether e-rhHsp70 promotes motoneuron survival by inhibiting these events directly or by affecting an upstream mechanism, e-rhHsp70 was added at selected times in culture to motoneurons deprived of MEx. In cultures deprived of trophic support, optimal motoneuron survival was achieved if e-rhHsp70 was added before $12 \mathrm{~h}$. Survival rates were $82.6 \%$ when e-rhHsp70 was added at plating versus $54.8,67.4$, and $51.3 \%$ when added at 12 , 16 , and $20 \mathrm{~h}$, respectively ( $n=2$ independent experiments with four to five wells per condition used in each experiment). Thus, for maximal effect, e-rhHsp70 must be added to cultures before the commitment of motoneurons to death and activation of cor- 

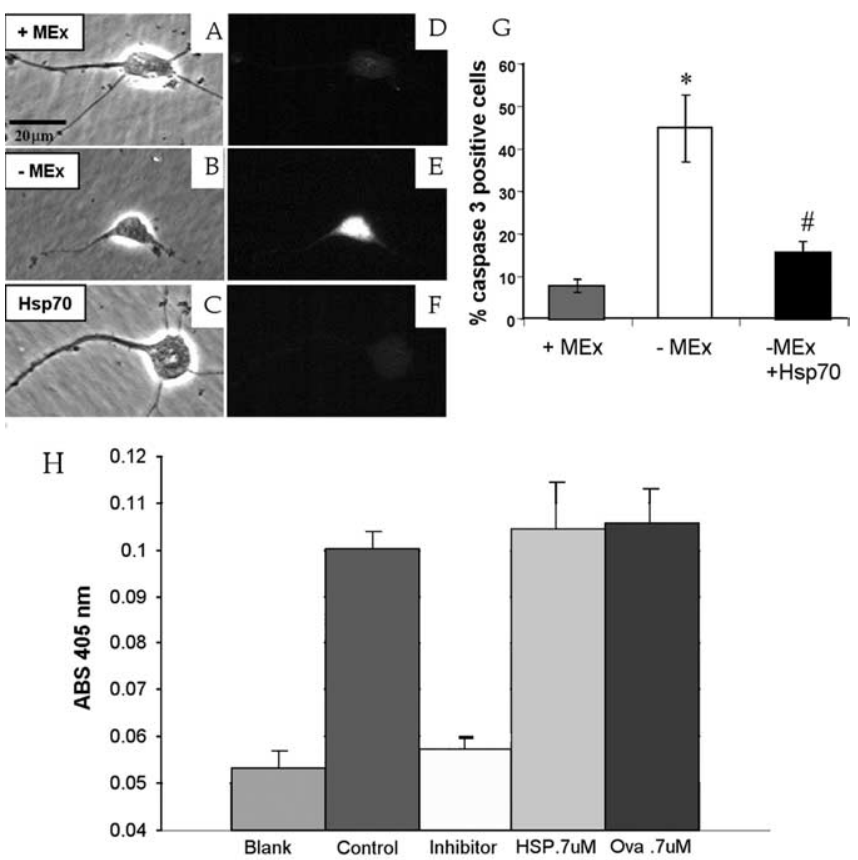

Figure 3. Caspase-3 activation is inhibited by Hsp70. Motoneurons were plated with or without trophic support (MEx) or without MEx but treated with recombinant human Hsp70 (75 $\mu \mathrm{g} / \mathrm{ml})$ for $24 \mathrm{~h}$ and fixed and stained with anti-cleaved caspase-3. Phase-contrast $(\boldsymbol{A}-\boldsymbol{C})$ and fluorescent $(\boldsymbol{D}-\boldsymbol{F})$ images are presented. Results are expressed as a percentage of positively labeled cells in each condition. As expected, cultures with no MEx showed significantly more activated caspase-3-immunoreactive cells compared with cultures with MEx $\left(\boldsymbol{G} ;{ }^{*} p<0.001\right)$. Cultures with e-rhHsp70 showed a significant reduction in staining for activated caspase-3 compared with cultures without MEx (G; $\left.{ }^{\#} p<0.001\right)$ and no difference compared with controls with MEx. Statistical significance was determined by ANOVA ( $n=3$ independent experiments with 3-4 wells per condition per experiment; error bars represent SEM). $\boldsymbol{H}$, Although caspase-3 activation was decreased in motoneurons deprived of MEx, but treated with Hsp70, we found no direct inhibition of activity by Hsp70. Hsp70, ovalbumin control protein, or the caspase inhibitor, DEVD, were added at equimolar amounts $(0.7 \mu \mathrm{m})$. Readings were taken every $2 \mathrm{~min}$ up to $10 \mathrm{~min}$, and then every $15 \mathrm{~min}$ up to the $90 \mathrm{~min}$ time point. ABS, Absorbance.

responding cell death-specific events. These results further suggest that e-rhHsp70 promotes motoneuron survival via upstream mechanisms, rather than by directly inhibiting cell death execution events.

\section{The presence of HSP70 in muscle extract is necessary for its survival-promoting ability}

To determine whether the presence of HSP70 is a component of the survival-promoting activity of MEx, we used a combination of ion exchange and ATP affinity columns to selectively reduce the concentration of HSP70 in MEx (Fig. 4A-D). Motoneurons treated with HSP70-depleted MEx showed a significant reduction in survival compared with controls treated with complete $\operatorname{MEx}$ (Fig. 4E). Interestingly, we noted that motoneurons treated with the MEx depleted of HSP70 died in a different manner than those deprived of MEx. We found that, after $24 \mathrm{~h}$ in culture, there was little difference in morphology, caspase activity, or ATP concentrations between cells cultured with MEx or HSP70-depleted MEx. However, by $72 \mathrm{~h}$ in culture, cells cultured with HSP70depleted MEx had clumped together and exhibited increased caspase activity and decreased ATP concentration when compared with cells supplied with MEx (data not shown). In contrast, motoneurons deprived of MEx have increased caspase activity and decreased utilization of ATP and are more phase-dark with shorter neurites compared with cells supplied with MEx at $24 \mathrm{~h}$, and by $72 \mathrm{~h}$, there are few remains of these cells. Importantly, we detected no differences in morphology or survival between cells supplied with MEx or the control MEx that underwent passage through the columns and reconstitution with HSP70 eluted off the ATP column. These results suggest that HSP70 is a critical factor in MEx for motoneuron survival in vitro. They also suggest that HSP70 may exert its trophic effect in a time-dependent manner, perhaps by mediating long-term delivery and/or utilization of other trophic factors, as well as possible interactions with the ability of the motoneuron to adhere to the substrate.

We also confirmed that the techniques used to remove HSP70 from MEx did not remove other Hsps (Fig. 4D). There was no change in apparent concentrations of Hsp27 or -40 . These results, together with those reported above, suggest that the presence of these proteins in MEx does not appear to account for its survivalpromoting activity. Interestingly, we appeared to detect increased amounts of Hsp90 in the Hsp70-depleted MEx (Fig. 4D). Hsp70 and -90 have been shown to interact (Carrello et al., 2004; Odunuga et al., 2004; Reyes-Del Valle et al., 2005), and we believe that the apparent increased amount of Hsp90 is a result of a dissociation of the Hsp70/90 complex during the ion exchange process, resulting in either increased antigenicity or increased free Hsp90. Interestingly, although addition of recombinant Hsp90 to motoneuron cultures did promote survival, it does not appear to be able to contribute to survival in MEx when Hsp70 is removed (Fig. 2H). The role of Hsp90 and the potential Hsp70/90 complex in promoting motoneuron survival is an area of future investigation.

Potential physiological sources of extracellular HSP70 exist in the limbs and spinal cord

The presence of Hsc70 and Hsp70 in the developing limb and in MEx is consistent with a potential trophic role for these proteins (Fig. 5A,B). Because secretion or release of Hsp70 from cultured rat embryo cells has been documented (Hightower and Guidon, 1989), we next investigated whether muscle cells actively secrete HSP70. Muscle cell cultures were prepared from E11 chick hindlimbs. After differentiation and fusion of myocytes, spontaneously contracting skeletal muscles were observed. Few, if any, dead cells were demonstrated by the Live/Dead kit (Invitrogen) (data not shown). Conditioned medium was collected after $24 \mathrm{~h}$ in culture and processed to detect HSP70. The protein was found in the muscle cell-conditioned medium, as well as in extracts of the cells (Fig. 5C).

Glial cells are another potential source of trophic support for motoneurons (Oppenheim et al., 2000), and cultured glioma cells were shown to release Hsp70 (Guzhova et al. 2001). To investigate whether primary astrocytes may be a physiological source of extracellular HSP70, lumbar spinal cord astrocyte cultures were prepared. These cultures were checked for dying cells and found to be healthy as described above for muscle cell cultures. Conditioned medium collected from astrocytes in culture for $24 \mathrm{~h}$ also exhibited detectable levels of secreted HSP70 (Fig. $5 D)$.

\section{Application of e-rhHsp70 protects spinal lumbar}

\section{motoneurons from naturally occurring cell death in vivo} Given that e-rhHsp70 supports motoneuron survival in vitro, that target (muscle) and supporting cells (glia) of motoneurons produce and release $\mathrm{Hsp} 70$, and that various preparations of Hsc70 and Hsp70 can increase survival of injured sensory and motoneurons (Houenou et al., 1996; Yu et al., 2001; Tidwell et al., 2004), we next determined whether application of e-rhHsp70 
would promote survival of motoneurons that normally would die during chick embryonic development in vivo (Chu-Wang and Oppenheim, 1978). Embryos treated in ovo by application of e-rhHsp70 to the chorioallantoic membrane on E6 and E7 exhibited a significant increase in the number of healthy motoneurons on E7.5 (Fig. 6), as well as a reduction in the number of pyknotic and activated caspase-3immunoreactive motoneurons (Fig. 7). Treatment with ovalbumin has no effect. These results indicate that e-rhHsp70 can be delivered systemically in vivo and promote motoneuron survival.

\section{Muscle does not appear to be a source of HSP70 to promote motoneuron survival during development}

Because systemically delivered e-rhHsp70 is trophic for motoneurons in vivo, we next examined whether muscle-derived HSP70 acted similarly and whether it could be retrogradely transported from muscle. We failed to detect labeled motoneurons in the sciatic nerve or spinal cord of E7.5 embryos whose hindlimbs were injected with biotinylated Hsp70 in ovo at E7, and did not detect increased levels in spinal cords as determined by Western blot analysis after injections (data not shown). For this reason, we do not believe that e-rhHsp70 is retrogradely transported from muscle to cell body. Furthermore, when e-rhHsp70 was injected into the entire hindlimb of E7.0 spinal cordhindlimb preparations, there was no increased motoneuron survival in the spinal cord ipsilateral to the injected limb compared with the contralateral spinal cord (Fig. 8). In contrast, in similar preparations in which glial-derived neurotrophic factor (GDNF) was injected into the hindlimb, increased motoneuron survival was demonstrated (Fig. 8). These results show that systemic, but not muscle-derived, e-rhHsp70 is sufficient to prevent motoneuron cell death.

\section{Spinal cord overexpression of $\mathrm{Hsp} 70$ is} sufficient to reduce motoneuron PCD The ability of systemically administered e-rhHsp70 to promote motoneuron survival suggests that an extracellular source of this protein can signal to motoneurons. To examine whether an intracellular source of Hsp70 could mediate similar survival effects, we overexpressed mouse Hsp70 in one-half of the lumbar spinal cord by in ovo electroporation (Gould and Oppenheim, 2004). cDNA for mouse Hsp70-1 together with GFP (mHSP70IRES2-GFP) under the influence of chick

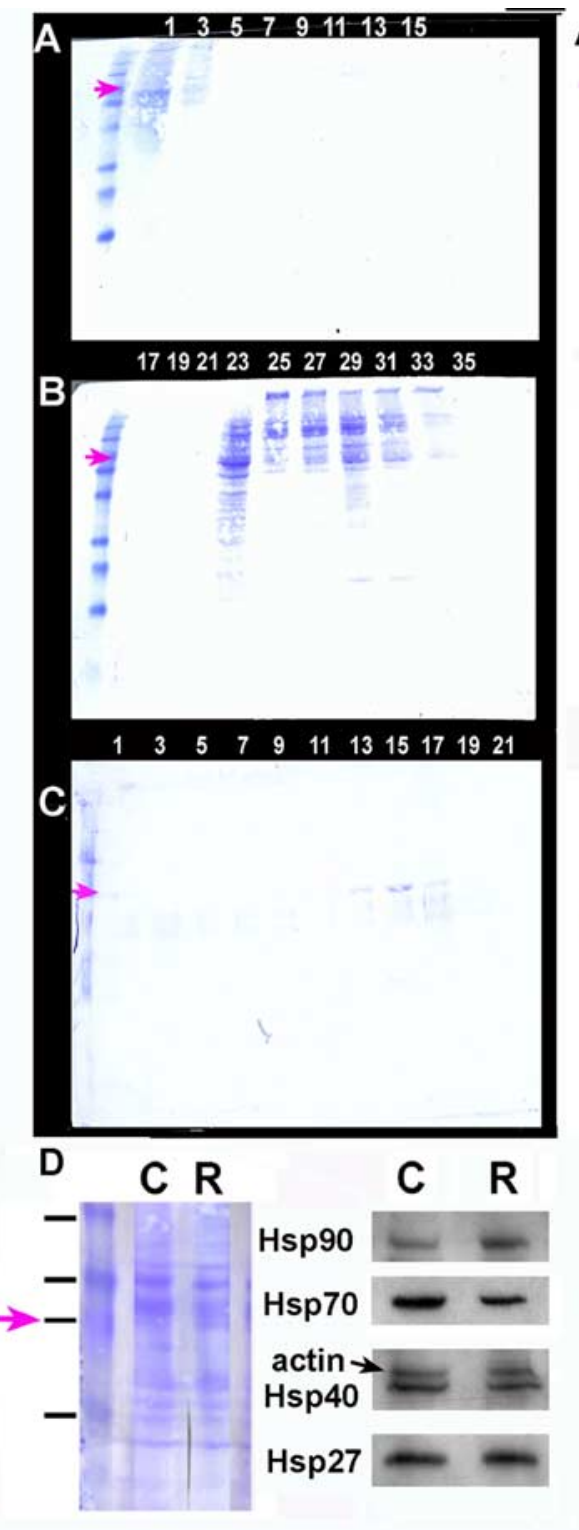

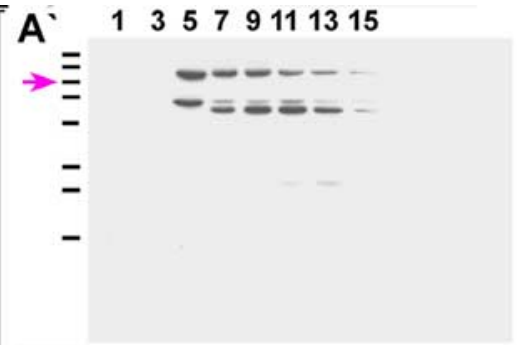

17192123252729313335 B'
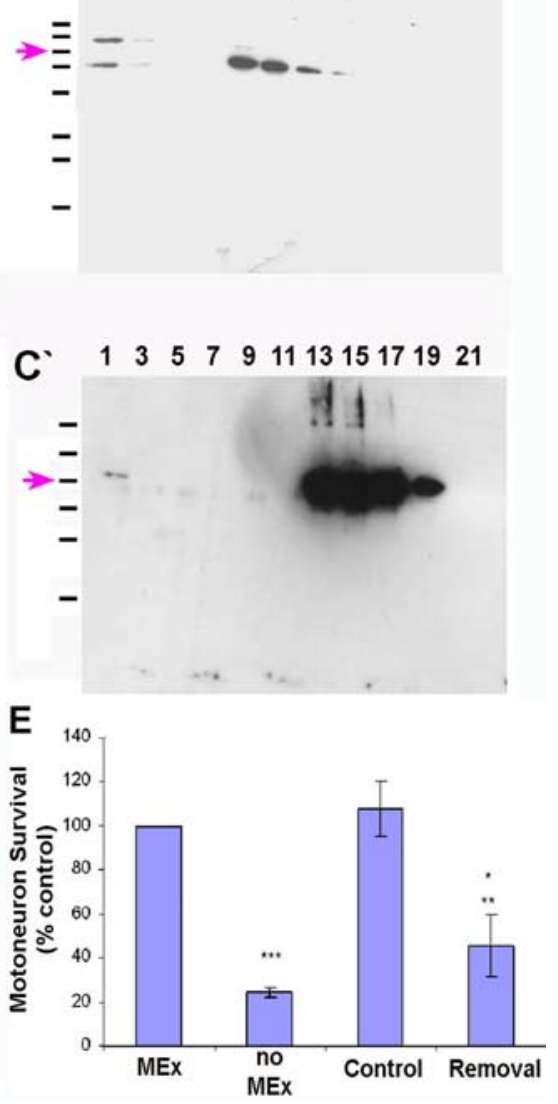

Figure 4. The removal of HSP70 from MEx reduces its survival-promoting activity. Coomassie-stained PVDF membranes ( $A$ and $\boldsymbol{B})$ and corresponding Western blots $\left(\boldsymbol{A}^{\prime}\right.$ and $\left.\boldsymbol{B}^{\prime}\right)$ resulting from ion exchange chromatography with DE-52 medium (Whatman) are shown. The pink arrow indicates the $64 \mathrm{kDa}$ marker on each membrane. Lane 1 shows the flow-through, and lane 3 shows the wash fraction, both of which show no immunoreactivity for HSP70, indicating that HSP70 is completely bound to the column. Fractions 5-31 show the elutions by a stepwise salt gradient of $100 \mathrm{~mm}$ (5-15), $125 \mathrm{~mm}$ (17-19), and $150 \mathrm{~mm}$ (23-31). Further increased salt concentrations ( $300 \mathrm{~mm}$ ) were used to elute the remainder of proteins contained in MEx (data not shown). Western blots of the elution fractions indicate the location of HSP70 (top band) and actin (bottom band; pink arrow indicates $65 \mathrm{kDa}$ marker). The fractions containing HSP70 were pooled, dialyzed into ATP column buffer B, and subjected to affinity chromatography on a (-8-linked ATP agarose column (Sigma). Coomassie-stained PVDF indicates intact HSP70 eluted in fractions 11-19 (C; lane 15). Corresponding Western blot $\left(\boldsymbol{C}^{\prime}\right)$ indicates that the protein is immunoreactive to Hsp70. After chromatography, the fractions from ion-exchange and noneluted ATP column were pooled ( $\boldsymbol{D}$; sample $\mathrm{R}$ for removal). As a control for the removal process, after chromatography, the fractions from ion-exchange and noneluted ATP column were pooled together with the ATP elution fractions containing the HSP70 bound to the column ( $\boldsymbol{D}$; sample ( for control). Pooled samples are dialyzed in PBS and lyophilized to concentrate them. Western blot and Coomassie analysis were performed to confirm the reduction of HSP70 in MEX (D). Western blot analysis indicates a diminished amount of HSP70 in the depleted sample (R) compared with the control (C). Western blot for actin and a Coomassie-stained membranes were used for loading controls and comparison of extract integrity. $\boldsymbol{E}$, Motoneurons were cultured either with trophic support (MEx), without trophic support (no MEx), with the control MEx (Control), or MEx in which both Hsc and Hsp70 were depleted from the extract (Removal). Those motoneurons treated with the depleted extract showed a significant decrease in the number of surviving cells compared with both MEx and the control extract. Results are presented as mean + SEM; $n=4$ independent experiments. Statistical significance was determined using ANOVA followed by Tukey-Kramer post hoc test. ${ }^{*} p \leq 0.05$ compared with MEx; ${ }^{* *} p \leq 0.01$ compared with control; ${ }^{* *} p \leq 0.001$ compared with MEx and control. 
A

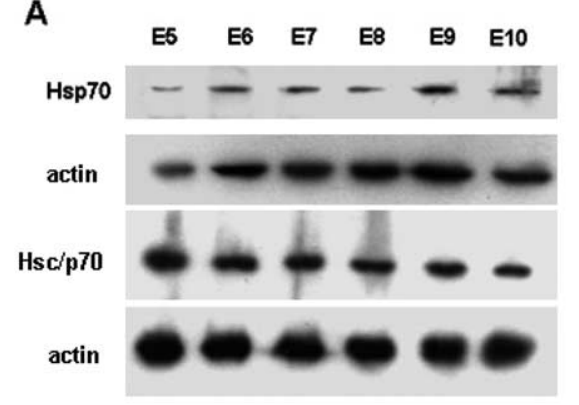

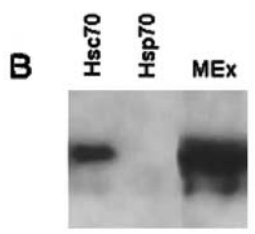

Hsc70

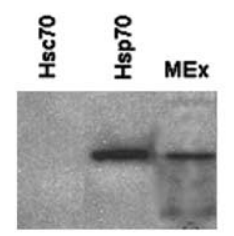

Hsp70
C

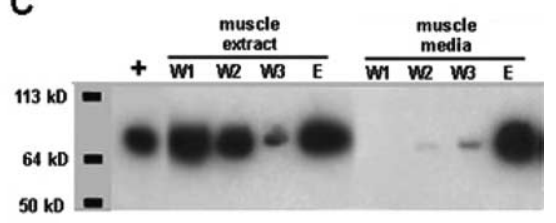

D

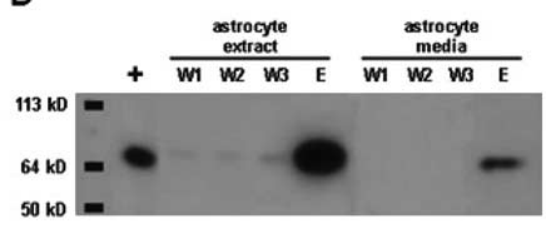

Figure 5. $A$, Levels of $\mathrm{Hsc}$ and $\mathrm{Hsp} 70$ were determined in developing musculature using monoclonal antibodies to either $\mathrm{Hsp} 70$ or Hsc/p70 (StressGen). Equal loading was confirmed by probing the blots for actin. A $1 \mathrm{~h}$ exposure time was necessary to detect the protein, suggesting that protein levels of $\mathrm{Hsp70}$ are lower that those for Hsc70. B. Muscle extract contains Hsc70 and Hsp70. Western blot analysis was used to determine whether $\mathrm{Hsc70}$ or $\mathrm{Hsp} 70$ are present in MEx ( 6 replicates). The antibodies are specific in that anti-Hsc70 does not recognize Hsp70 and vice versa. C, Muscle cells and muscle cell-conditioned medium contain HSP70. Protein from muscle cells in culture, and medium from these cultures, was incubated with ATP-agarose beads, eluted with $3 \mathrm{~mm}$ ATP, and TCA precipitated. Protein precipitates were fractionated on an SDS-PAGE gel, transferred to Immobilon P membrane (Millipore, Bedford, MA) and probed for HSP70. + refers to MEx; W1, W2, W3 refer to ATP-agarose bead washes; and E refers to ATP-agarose eluted proteins. D, Astrocytes secrete HSP70 into the culture medium. Protein from astrocytes in culture and medium from these cultures was treated as in C. Astrocyte cell protein extracts and conditioned medium from these cells contained HSP70.

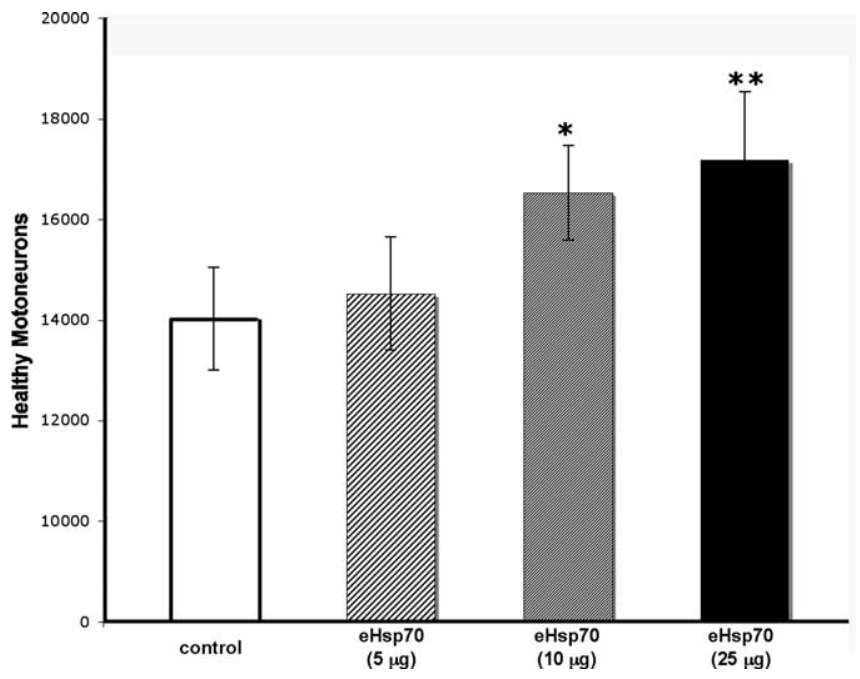

Figure 6. Administration of e-rhHsp70 in ovo prevents naturally occurring motoneuron programmed cell death. Chick embryos were treated with recombinant $\mathrm{Hsp} 70$ at indicated doses on E6 and E7. Embryos were killed on E7.5. After tissue fixation and processing, healthy motoneurons were counted. Embryos treated with both 10 and $25 \mu \mathrm{g}$ of recombinant protein had significantly greater numbers of healthy motoneurons compared with control and 5- $\mu \mathrm{g}$ Hsp70-treated embryos. There was no statistical difference between the 10- and 25- $\mu \mathrm{g}$ treated animals. Statistical significance was determined by ANOVA followed by Tukey-Kramer post hoc test. ${ }^{*} p \leq 0.05 ;{ }^{* *} p \leq 0.01$. Error bars indicate SE.

$\beta$-actin regulatory sequences was electroporated into one-half of the E3 chick embryo neural tube. The result was expression of mouse GFP in many motoneurons and other cells within the spinal cord (Fig. 9). Importantly, at E6, a time before motoneuron $\mathrm{PCD}$, equal numbers of motoneurons were detected in electroporated and control, unelectroporated motor columns, indi- cating that overexpression of this protein did not alter normal motoneuron development (data not shown). To evaluate the biological effects of overexpression of mHsp70-IRES2-GFP, we examined cellular expression patterns of mouse Hsp70/ GFP in electroporated neurons, verified full-length expression of Hsp70 on immunoblots, and counted the number of pyknotic motoneurons at E7.5, the peak of motoneuron cell death (Fig. 9) (data not shown). mHsp70-IRES2-GFP transfected spinal cord contains significantly fewer pyknotic or dying motoneurons than control IRES2-GFP electroporated spinal cord $(415 \pm 98, n=4$, vs $817 \pm 213, n=6$; $p<0.005$ as determined by Student's $t$ test). There was also a significant reduction of activated caspase- 3 immunoreactivity spinal cords transfected with Hsp70 compared with controls (data not shown). Because both motoneurons themselves and additional cell types within the spinal cord expressed the transgene, however, it is not clear whether the rescue effect originates from motoneuron-autonomous expression of Hsp70, or expression and secretion by other cell types.

\section{Discussion}

Motoneuron dependence on trophic factor support has been well established; however, many specific aspects of this dependence remain undefined. For example, limb MEx promotes motoneuron survival better than any individual trophic factor, but the specific components of MEx that are responsible for its survivalpromoting activity are not known. No individual factor appears to promote complete survival of a motoneuron population, and clinical studies for the use of trophic factors to promote motoneuron survival in ALS have failed (Henderson, 1996; Miller et al., 1996; Oppenheim, 1996; Borasio et al., 1998; The BDNF Study Group, 1999). Although there are several possible explanations, these data considered with our results suggest that optimal motoneuron survival may require other agents, such as HSP70 in addition to trophic factors. Hsc70 and Hsp70 are present in motoneurons, but no increase in endogenous expression is observed in the face of either insufficient trophic factor or the classical stressful stimulus, heat shock. Nonetheless, other events associated with cellular stress, such as increased expression of Hsp27, -40 , and -90 occur after prototypic heat stress. This apparent inability to appropriately increase expression of Hsp or Hsc70 may render motoneurons vulnerable to metabolic stress.

Our results demonstrating the inability of motoneurons to increase expression of $\mathrm{Hsc70}$ or Hsp70 are not without precedent. After sciatic nerve crush, expression of Hsp27 and Hsp90, but not Hsp70, increased in spinal motoneurons. In this model system, the increase of Hsp70 was observed in the lateral motor column of the spinal cord (Kalmar et al. 2002). Recently, it has been proposed that motoneurons fail to induce HSP70 because they fail to activate heat shock transcription factor (HSF-1) (Batulan et al., 2003). However, motoneurons are capable of upregulating the other Hsps (i.e., Hsp27, -40 , and 90) that are regulated by HSF-1, suggesting that mechanisms other than HSF-1 activation must be involved in regulating HSP70 expression. Availability of 

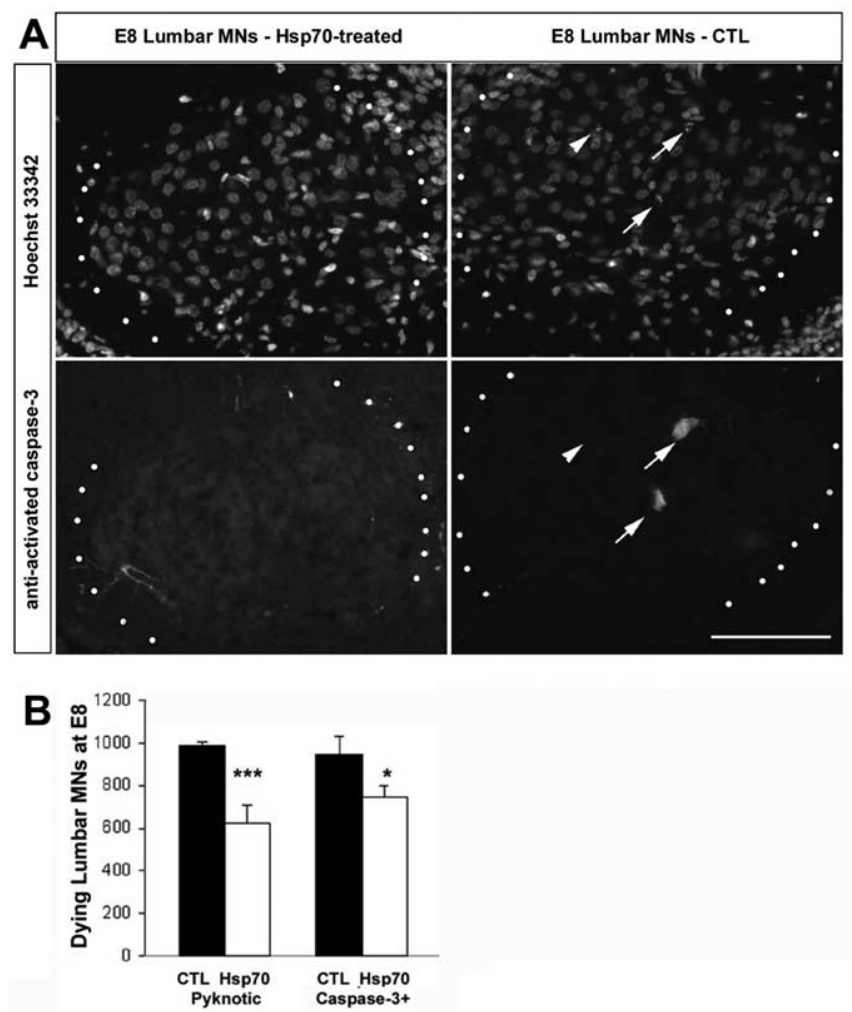

Figure 7. Administration of e-rhHsp70 reduces the number of dying motoneurons in vivo. $A$, Transverse sections of the lumbar spinal cord at E8 labeled with Hoechst 33342 to reveal pyknotic motoneurons (top panels) or probed with an activated caspase- 3 antibody to count apoptotic motoneurons (bottom panels) after in ovo treatment at $\mathrm{E} 6$ and $\mathrm{E} 7$ with $25 \mu \mathrm{g}$ of e-rhHsp70 or saline [control (CTL)]. Arrows illustrate pyknotic nuclei that also exhibit activated caspase-3 immunoreactivity, whereas the arrowhead indicates a pyknotic motoneuron without activated caspase-3 immunostaining. White dots encircle the lumbar lateral motor column; medial is to the right and lateral to the left. Scale bar, $50 \mu \mathrm{m}$. B, Quantification of the antiapoptotic effects of administration of e-rhHsp70 in vivo. e-rhHsp70 at E6 and E7 significantly reduced the number of Hoechst-labeled pyknotic motoneurons in the lumbar spinal cord $\left({ }^{* *} p<\right.$ $0.001 ; n=6$ ), as well as the number of activated caspase-3-immunoreactive motoneurons $\left({ }^{*} p<0.05 ; n=3\right)$. Statistical significance was determined by Student's $t$ test. Error bars indicate SE. MN, Motoneuron.

extracellular Hsp70 may therefore play a compensatory role after stress to promote maintenance of survival pathways, and/or inhibit activation of cell death-specific events. Several recent studies have indicated that Hsp70 may interact with and/or inhibit cell death-specific components, such as AIF (apoptosis-inducing factor), Apaf-1, or caspases (Beere et al., 2000; Saleh et al., 2000; Komarova et al., 2004; Matsumori et al., 2005). Our results show that, although administration of e-rhHsp70 results in reduced caspase activity in motoneurons, it does not interact directly with caspases. This result is in agreement with a recently published report by Ran et al. (2004). Furthermore, optimal survivalpromoting activity is observed when e-rhHsp70 is added early and well before the commitment to death in trophic factordeprived cultures. Our previous work indicates that, to be effective, caspase inhibitors had to be added later during the time of caspase activation (between 14 and $24 \mathrm{~h}$ ), rather than directly at plating (Milligan et al., 1995). These results support the hypothesis that e-rhHsp70 promotes survival by a mechanism other than direct interaction with cell death-specific components.

Secretion of Hsp70 has been shown to occur in a number of animal model systems and in humans, where it is found in the blood (Febbraio et al., 2002; Pockley et al., 2002). It has been
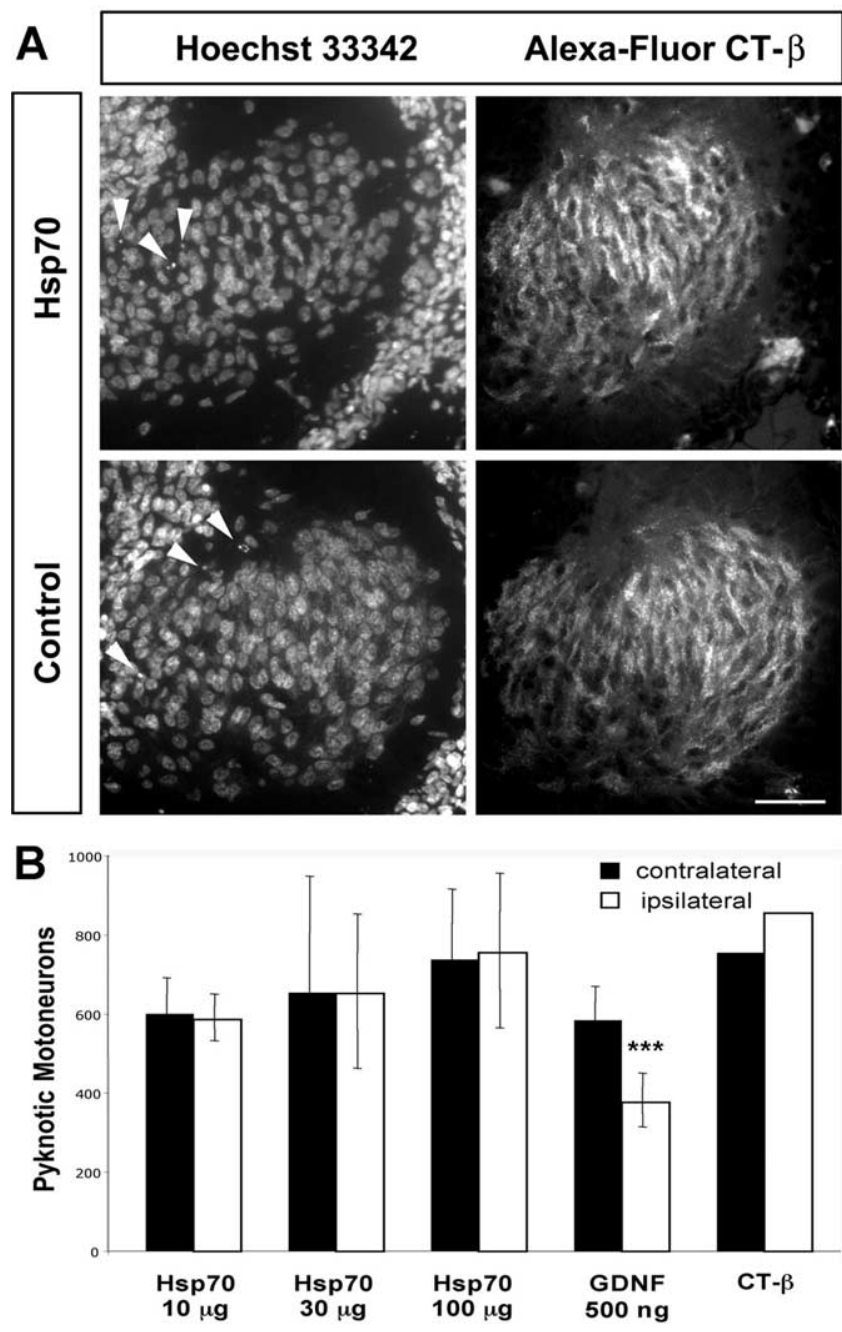

Figure 8. Hsp70 from muscle does not reduce the number of dying motoneurons in vivo. Hindlimb injections with either saline or human recombinant Hsp70 (StressGen) at the indicated doses, together with the retrograde tracer Alexa Fluor 594-conjugated cholera toxin- $\beta$, fail to prevent motoneuron cell death in ex vivo spinal cord/hindlimb preparations. $\boldsymbol{A}$, Spinal cord sections of muscle-injected embryos were labeled with Hoechst 33342 (left panels) to illustrate pyknotic motoneurons (arrowheads) or fluorescent cholera toxin- $\beta$ to indicate motoneurons affected by treatment (right panels). Scale bar, $50 \mu \mathrm{m}$. $\boldsymbol{B}$, The numbers of pyknotic nuclei within retrogradely labeled areas of the ipsilateral motor column were significantly reduced by injections of GDNF $\left(n=6\right.$; $\left.{ }^{* * *} p<0.001\right)$, but not e-rhHsp70 ( $n=4$ for each dose) or saline (CT- $\beta ; n=2$ ) into hindlimb muscles (Gould and Oppenheim, 2004). Statistical significance determined by ANOVA followed by Tukey-Kramer post hoc test. Error bars indicate SE. CT, Cholera toxin.

suggested that this extracellular Hsp70 interacts with cells it contacts (Hightower and Guidon, 1989; Guzhova et al., 2001; Broquet et al., 2003). Furthermore, in monocytes, extracellular Hsp70 has been shown to function as a cytokine (Asea et al., 2000) and those cells were found to have a Toll-like surface receptor for Hsp70 (Asea et al., 2002). In B cells, CD40 appears to serve as an extracellular receptor for binding and uptake of Hsp70 (Becker et al., 2002). Whether such receptors exist and bind Hsp70 in neurons has not been investigated. However, in addition to such receptor-mediated activity, there is evidence that HSP70 can be internalized and readily imported into both cytoplasmic and nuclear compartments of arterial smooth muscle cells, U937 cells, lymphocytes, retinal ganglion cells, and neuroblastoma cells (Johnson et al., 1990, 1995; Guzhova et al., 1998; Fujihara and Nadler, 1999; Guzhova et al., 2001; Yu et al., 2001). 

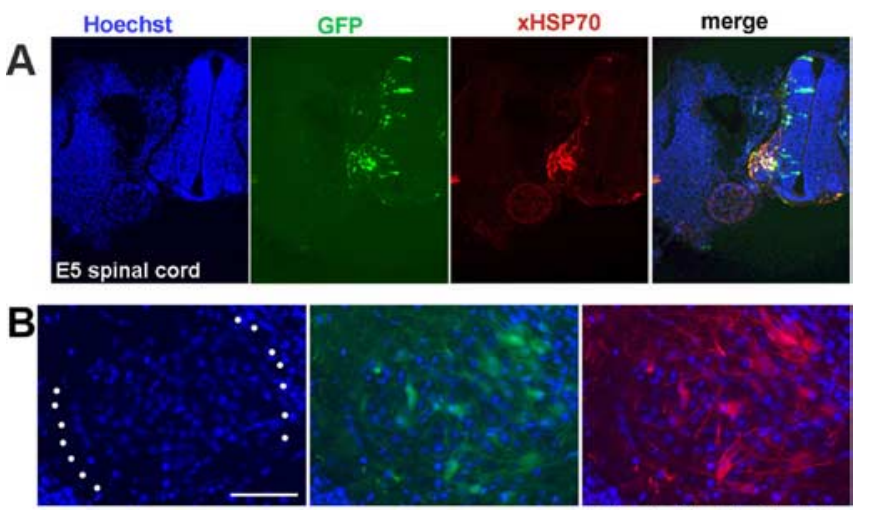

E8 Lumbar MNs Hoeschst

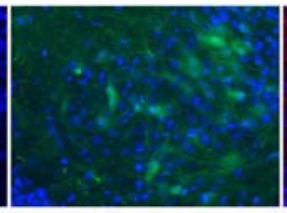

Hoechst/GPF

Hoechst/ anti-mHsp70
Figure 9. CNS-derived Hsp70 promotes motoneuron survival. $\boldsymbol{A}$, Transverse section of the lumbar spinal cord at E8 labeled with Hoechst 33342 (blue), GFP (green), or an antibody against mouse Hsp70 (red) after in ovo electroporation at E3 with a plasmid expressing mouse Hsp70IRES2-GFP under the control of the chicken $\beta$-actin/CMV promoter. $\boldsymbol{B}$, Enlarged images of the lateral motor column; white dots encircle the LMC. Scale bar, $50 \mu \mathrm{m}$.

In both arterial smooth muscle cells in culture and retinal ganglion cells in vivo, extracellular $\mathrm{Hsc} / \mathrm{Hsp} 70$ promoted survival after nutrient deprivation or light damage, respectively (Johnson et al., 1995; Yu et al., 2001).

HSP70 is present in hindlimb MEx and in medium collected from cultured skeletal muscle cells. When HSP70 is removed from MEx, the survival-promoting activity of MEx is significantly reduced. Although these results suggest that HSP70s are necessary for MEx-mediated rescue of trophic-deprived motoneurons in vitro, muscle-injected e-rhHsp70 is not sufficient to rescue additional motoneurons in an ex vivo preparation. Additionally, we did not detect retrograde transport of HSP70 by intact motoneurons in vitro or in vivo, in contrast to previous studies of injured axons that suggest that these proteins can enter the axon and be retrogradely transported (Houenou et al., 1996; Tidwell et al., 2004). Although muscle may not be a physiological source of extracellular HSP70 for motoneurons, adaxonal glial cells such as Schwann cells can serve as a source of this HSP70 for the axon as suggested in other model systems (Tytell et al., 1986; Edbladh et al., 1994). Nonetheless, the requirement of this source of the protein for neuronal survival has not been established. Together, these reports suggest that the environment and state of the motoneuron (healthy or injured) determines whether and how exogenous HSP70 promotes survival.

Nonetheless, administration of e-rhHsp70 to the chorioallantoic membrane of the developing chick reduced the amount of naturally occurring motoneuron death observed between E7.5 and E8.0. What, then, is the cellular mechanism by which systemic Hsp70 regulates motoneuron survival? We provide evidence that astrocytes secrete HSP70 proteins. Additionally, astrocyte-conditioned medium potently rescues motoneurons (data not shown). Furthermore, astrocytes and other glia are capable of regulating motoneuron survival during development and after injury (Oppenheim et al., 2000; Banks and Noakes, 2002). Unfortunately, electroporation of either cultured chick astrocytes or E3 chick spinal cord with a plasmid containing GFP under the expression of the human GFAP promoter failed to result in the expression of GFP (data not shown). Other experiments aimed at elucidating the precise contribution of astrocytes and astrocytic HSP70 to motoneuron survival are ongoing.

In contrast, Hsp70 overexpression in the spinal cord is also sufficient to prevent motoneurons from undergoing PCD in vivo. Three possible interpretations arise from these data: (1) motoneuron-derived intracellular Hsp70 is neurotrophic, (2) motoneuron-derived extracellular Hsp70 is neurotrophic in an autocrine manner, and (3) non-motoneuron-derived extracellular Hsp70 is neurotrophic in a paracrine manner. The second two possibilities may explain why systemically delivered, but not muscle-injected e-rhHsp70, rescues motoneurons in vivo. Centrally, but not distally, supplied Hsp70 is trophic for motoneurons. This observation further suggests that motor endplates are incapable of responding to HSP70, even if it is overexpressed in the muscle, whereas the axons and cell bodies can respond to extracellular HSP70. Additional experiments using a motoneuron-specific promoter to drive HSP70 expression will help explain the relative importance of motoneuron or nonmotoneuron sources of the protein in achieving the rescue effect.

The present results provide additional support for the interdependence of motoneurons on target, on centrally located glial cells, and on themselves. Considering the size of and metabolic demands on motoneurons, it is possible that these cells are only capable of synthesizing amounts of Hsc70 or Hsp70 necessary for maintenance of cell function and survival. They do not appear able to increase production in response to the greater demands of stressful stimuli. The extracellular HSP70 derived from other cell types may compensate for this deficit. It is conceivable, therefore, that in situations of environmental stress, the amount of extracellular HSP70 available to motoneurons becomes limited as utilization of these proteins may be increased by themselves and surrounding cells. This situation would then place the motoneurons in a compromised position of insufficient access to HSP70 and thus render them more susceptible to damage and death than they would be if HSP70 were more abundant. The results presented here suggest a critical role for extracellular HSP70 in promoting motoneuron survival. Motoneuron survival may then be dependent on a balance of receipt of specific trophic factors and extracellular HSP70 derived from target and CNS cells, respectively, with one factor alone being insufficient to promote optimal survival.

\section{References}

Appel SH (1981) A unifying hypothesis for the cause of amyotrophic lateral sclerosis, parkinsonism, and Alzheimer disease. Ann Neurol 10:499-505. Asea A, Kraeft SK, Kurt-Jones EA, Stevenson MA, Chen LB, Finberg RW, Koo GC, Calderwood SK (2000) HSP70 stimulates cytokine production through a CD14-dependant pathway, demonstrating its dual role as a chaperone and cytokine. Nat Med 6:435-442.

Asea A, Rehli M, Kabingu E, Boch JA, Bare O, Auron PE, Stevenson MA, Calderwood SK (2002) Novel signal transduction pathway utilized by extracellular HSP70: role of Toll-like receptor (TLR) 2 and TLR4. J Biol Chem 277:15028-15034.

Banks GB, Noakes PG (2002) Elucidating the molecular mechanisms that underlie the target control of motoneuron death. Int $\mathrm{J}$ Dev Biol 46:551-558.

Barnes NY, Li L, Yoshikawa K, Schwartz LM, Oppenheim RW, Milligan CE (1998) Increased production of amyloid precursor protein provides a substrate for caspase-3 in dying motoneurons. J Neurosci 18:5869-5880.

Batulan Z, Shinder GA, Minotti S, He BP, Doroudchi MM, Nalbantoglu J, Strong MJ, Durham HD (2003) High threshold for induction of the stress response in motor neurons is associated with failure to activate HSF1. J Neurosci 23:5789-5798.

Becker T, Hartl FU, Wieland F (2002) CD40, an extracellular receptor for binding and uptake of Hsp70. J Cell Biol 158:1277-1285.

Beere HM, Wolf BB, Cain K, Mosser DD, Mahboubi A, Kuwana T, Tailor P, Morimoto RI, Cohen GM, Green DR (2000) Heat-shock protein 70 inhibits apoptosis by preventing recruitment of procaspase- 9 to the Apaf-1 apoptosome. Nat Cell Biol 2:469-475. 
Borasio GD, Robberecht W, Leigh PN, Emile J, Guiloff RJ, Jerusalem F, Silani V, Vos PE, Wokke JH, Dobbins T (1998) A placebo-controlled trial of insulin-like growth factor-I in amyotrophic lateral sclerosis. European ALS/IGF-I Study Group. Neurology 51:583-586.

Broquet AH, Thomas G, Masliah J, Trugnan G, Bachelet M (2003) Expression of the molecular chaperone Hsp70 in detergent-resistant microdomains correlates with its membrane delivery and release. J Biol Chem 278:21601-21606.

Brown CR, Martin RL, Hansen WJ, Beckmann RP, Welch WJ (1993) The constitutive and stress inducible forms of hsp 70 exhibit functional similarities and interact with one another in an ATP-dependent fashion. J Cell Biol 120:1101-1112.

Brown IR (1991) Expression of heat shock genes (hsp70) in the mammalian nervous system. Results Probl Cell Differ 17:217-229.

Buzzard KA, Giaccia AJ, Killender M, Anderson RL (1998) Heat shock protein 72 modulates pathways of stress-induced apoptosis. J Biol Chem 273:17147-17153.

Carrello A, Allan RK, Morgan SL, Owen BA, Mok D, Ward BK, Minchin RF, Toft DO, Ratajczak T (2004) Interaction of the Hsp90 cochaperone cyclophilin 40 with Hsc70. Cell Stress Chaperones 9:167-181.

Chu-Wang IW, Oppenheim RW (1978) Cell death of motoneurons in the chick embryo spinal cord. II. A quantitative and qualitative analysis of degeneration in the ventral root, including evidence for axon outgrowth and limb innervation prior to cell death. J Comp Neurol 177:59-85.

Clarke PG, Oppenheim RW (1995) Neuron death in vertebrate development: in vitro methods. Methods Cell Biol 46:277-321.

Crews LL, Wigston DJ (1990) The dependence of motoneurons on their target muscle during postnatal development of the mouse. J Neurosci 10:1643-1653.

Dohrmann U, Edgar D, Sendtner M, Thoenen H (1986) Muscle-derived factors that support survival and promote fiber outgrowth from embryonic chick spinal motor neurons in culture. Dev Biol 118:209-221.

Eagleson KL, Haun F, Cunningham TJ (1990) Different populations of dorsal lateral geniculate nucleus neurons have concentration-specific requirements for a cortically derived neuron survival factor. Exp Neurol 110:284-290.

Edbladh M, Ekstrom PA, Edstrom A (1994) Retrograde axonal transport of locally synthesized proteins, e.g., actin and heat shock protein 70 , in regenerating adult frog sciatic sensory axons. J Neurosci Res 38:424-432.

Febbraio MA, Ott P, Nielsen HB, Steensberg A, Keller C, Krustrup P, Secher $\mathrm{NH}$, Pedersen BK (2002) Exercise induces hepatosplanchnic release of heat shock protein 72 in humans. J Physiol (Lond) 544:957-962.

Fujihara SM, Nadler SG (1999) Intranuclear targeted delivery of functional NF-kappaB by $70 \mathrm{kDa}$ heat shock protein. EMBO J 18:411-419.

Gabai VL, Meriin AB, Mosser DD, Caron AW, Rits S, Shifrin VI, Sherman MY (1997) Hsp70 prevents activation of stress kinases. A novel pathway of cellular thermotolerance. J Biol Chem 272:18033-18037.

Gould TW, Oppenheim RW (2004) The function of neurotrophic factor receptors expressed by the developing adductor motor pool in vivo. J Neurosci 24:4668-4682.

Guzhova I, Kislyakova K, Moskaliova O, Fridlanskaya I, Tytell M, Cheetham M, Margulis B (2001) In vitro studies show that Hsp70 can be released by glia and that exogenous Hsp70 can enhance neuronal stress tolerance. Brain Res 914:66-73.

Guzhova IV, Arnholdt AC, Darieva ZA, Kinev AV, Lasunskaia EB, Nilsson K, Bozhkov VM, Voronin AP, Margulis BA (1998) Effects of exogenous stress protein 70 on the functional properties of human promonocytes through binding to cell surface and internalization. Cell Stress Chaperones 3:67-77.

Hartl FU (1996) Molecular chaperones in cellular protein folding. Nature 381:571-579.

Henderson CE (1996) Role of neurotrophic factors in neuronal development. Curr Opin Neurobiol 6:64-70.

Hightower LE, Guidon Jr PT (1989) Selective release from cultured mammalian cells of heat-shock (stress) proteins that resemble glia-axon transfer proteins. J Cell Physiol 138:257-266.

Houenou LJ, Li L, Lei M, Kent CR, Tytell M (1996) Exogenous heat shock cognate protein Hsc 70 prevents axotomy-induced death of spinal sensory neurons. Cell Stress Chaperones 1:161-166.

Johnson AD, Berberian PA, Bond MG (1990) Effect of heat shock proteins on survival of isolated aortic cells from normal and atherosclerotic cynomolgus macaques. Atherosclerosis 84:111-119.
Johnson AD, Berberian PA, Tytell M, Bond MG (1995) Differential distribution of $70-\mathrm{kD}$ heat shock protein in atherosclerosis. Its potential role in arterial SMC survival. Arterioscler Thromb Vasc Biol 15:27-36.

Kalmar B, Burnstock G, Vrbova G, Greensmith L (2002) The effect of neonatal nerve injury on the expression of heat shock proteins in developing rat motoneurones. J Neurotrauma 19:667-679.

Kiang JG, Tsokos GC (1998) Heat shock protein 70 kDa: molecular biology, biochemistry, and physiology. Pharmacol Ther 80:183-201.

Komarova EY, Afanasyeva EA, Bulatova MM, Cheetham ME, Margulis BA, Guzhova IV (2004) Downstream caspases are novel targets for the antiapoptotic activity of the molecular chaperone hsp70. Cell Stress Chaperones 9:265-275.

Lasunskaia EB, Fridlianskaia II, Guzhova IV, Bozhkov VM, Margulis BA (1997) Accumulation of major stress protein $70 \mathrm{kDa}$ protects myeloid and lymphoid cells from death by apoptosis. Apoptosis 2:156-163.

Latchman DS (1995) Cell stress genes and neuronal protection. Neuropathol Appl Neurobiol 21:475-477.

Levison SW, McCarty KD (1991) Astroglia in culture. In: Cuturing nerve cells (Banker G, Goslin K, eds), pp 309-336. Cambridge, MA: MIT.

Li L, Prevette D, Oppenheim RW, Milligan CE (1998) Involvement of specific caspases in motoneuron cell death in vivo and in vitro following trophic factor deprivation. Mol Cell Neurosci 12:157-167.

Li L, Oppenheim RW, Milligan CE (2001) Characterization of the execution pathway of developing motoneurons deprived of trophic support. J Neurobiol 46:249-264.

Lindquist S, Craig EA (1988) The heat-shock proteins. Annu Rev Genet 22:631-677.

Mallouk Y, Vayssier-Taussat M, Bonventre JV, Polla BS (1999) Heat shock protein 70 and ATP as partners in cell homeostasis (Rev). Int J Mol Med $4: 463-474$.

Matsumori Y, Hong SM, Aoyama K, Fan Y, Kayama T, Sheldon RA, Vexler ZS, Ferriero DM, Weinstein PR, Liu J (2005) Hsp70 overexpression sequesters AIF and reduces neonatal hypoxic/ischemic brain injury. J Cereb Blood Flow Metab 25:899-910.

Michler-Stuke A, Wolff J, Bottenstein J (1984) Factors influencing astrocyte growth and development in defined media. Int J Dev Neurosci 2:575-584.

Miller RG, Bryan WW, Dietz MA, Munsat TL, Petajan JH, Smith SA, Goodpasture JC (1996) Toxicity and tolerability of recombinant human ciliary neurotrophic factor in patients with amyotrophic lateral sclerosis. Neurology 47:1329-1331.

Milligan CE, Oppenheim RW, Schwartz LM (1994) Motoneurons deprived of trophic support in vitro require new gene expression to undergo programmed cell death. J Neurobiol 25:1005-1016.

Milligan CE, Prevette D, Yaginuma H, Homma S, Cardwell C, Fritz LC, Tomaselli KJ, Oppenheim RW, Schwartz LM (1995) Peptide inhibitors of the ICE protease family arrest programmed cell death of motoneurons in vivo and in vitro. Neuron 15:385-393.

Mosser DD, Caron AW, Bourget L, Denis-Larose C, Massie B (1997) Role of the human heat shock protein hsp70 in protection against stress-induced apoptosis. Mol Cell Biol 17:5317-5327.

Nakata N, Kato H, Kogure K (1993) Inhibition of ischaemic tolerance in the gerbil hippocampus by quercetin and anti-heat shock protein-70 antibody. NeuroReport 4:695-698.

Neville C, Rosenthal N, McGrew M, Bogdanova N, Hauschka S (1998) Skeletal muscle cultures. In: Methods in cell biology, Vol 52, pp 85-114. San Diego: Academic.

Nollen EA, Morimoto RI (2002) Chaperoning signaling pathways: molecular chaperones as stress-sensing "heat shock" proteins. J Cell Sci 115:2809-2816.

Odunuga OO, Longshaw VM, Blatch GL (2004) Hop: more than an Hsp70/ Hsp90 adaptor protein. BioEssays 26:1058-1068.

Oppenheim RW (1996) Neurotrophic survival molecules for motoneurons: an embarrassment of riches. Neuron 17:195-197.

Oppenheim RW, Haverkamp LJ, Prevette D, McManaman JL, Appel SH (1988) Reduction of naturally occurring motoneuron death in vivo by a target-derived neurotrophic factor. Science 240:919-922.

Oppenheim RW, Houenou LJ, Parsadanian AS, Prevette D, Snider WD, Shen L (2000) Glial cell line-derived neurotrophic factor and developing mammalian motoneurons: regulation of programmed cell death among motoneuron subtypes. J Neurosci 20:5001-5011.

Pockley AG, De Faire U, Kiessling R, Lemne C, Thulin T, Frostegard J (2002) 
Circulating heat shock protein and heat shock protein antibody levels in established hypertension. J Hypertens 20:1815-1820.

Punyiczki M, Fesus L (1998) Heat shock and apoptosis. The two defense systems of the organism may have overlapping molecular elements. Ann NY Acad Sci 851:67-74.

Rajdev S, Hara K, Kokubo Y, Mestril R, Dillmann W, Weinstein PR, Sharp FR (2000) Mice overexpressing rat heat shock protein 70 are protected against cerebral infarction. Ann Neurol 47:782-791.

Ran R, Zhou G, Lu A, Zhang L, Tang Y, Rigby AC, Sharp FR (2004) Hsp70 mutant proteins modulate additional apoptotic pathways and improve cell survival. Cell Stress Chaperones 9:229-242.

Reyes-Del Valle J, Chavez-Salinas S, Medina F, Del Angel RM (2005) Heat shock protein 90 and heat shock protein 70 are components of dengue virus receptor complex in human cells. J Virol 79:4557-4567.

Rubio E, Valenciano AI, Segundo C, Sanchez N, de Pablo F, de la Rosa EJ (2002) Programmed cell death in the neurulating embryo is prevented by the chaperone heat shock cognate 70. Eur J Neurosci 15:1646-1654.

Saleh A, Srinivasula SM, Balkir L, Robbins PD, Alnemri ES (2000) Negative regulation of the Apaf-1 apoptosome by Hsp70. Nat Cell Biol 2:476-483.

Samali A, Orrenius S (1998) Heat shock proteins: regulators of stress response and apoptosis. Cell Stress Chaperones 3:228-236.

Sato N, Wang S, Li L, Okabe K, Hashimoto M, Yaginuma H, Mikoshiba K, Uchiyama Y, Uetsuki T, Yoshikawa K, Milligan CE, Oppenheim RW (1998) A novel strategy for introducing exogenous bcl-2 into neuronal cells: the Cre/loxP system-mediated activation of bcl-2 for preventing programmed cell death using recombinant adenoviruses. Mol Cell Neurosci 12:65-78.
Schumacher RJ, Hansen WJ, Freeman BC, Alnemri E, Litwack G, Toft DO (1996) Cooperative action of Hsp70, Hsp90, and DnaJ proteins in protein renaturation. Biochemistry 35:14889-14898.

Sharp FR, Massa SM, Swanson RA (1999) Heat-shock protein protection. Trends Neurosci 22:97-99.

Tavaria M, Gabriele T, Kola I, Anderson RL (1996) A hitchhiker's guide to the human Hsp70 family. Cell Stress Chaperones 1:23-28.

The BDNF Study Group (1999) A controlled trial of recombinant methionyl human BDNF in ALS: The BDNF Study Group (Phase III). Neurology 52:1427-1433.

Tidwell JL, Houenou LJ, Tytell M (2004) Administration of Hsp70 in vivo inhibits motor and sensory neuron degeneration. Cell Stress Chaperones 9:88-98.

Tytell M, Greenberg SG, Lasek RJ (1986) Heat shock-like protein is transferred from glia to axon. Brain Res 363:161-164.

Vayssier M, Polla BS (1998) Heat shock proteins chaperoning life and death. Cell Stress Chaperones 3:221-227.

Welch WJ, Feramisco JR (1985) Rapid purification of mammalian 70,000dalton stress proteins: affinity of the proteins for nucleotides. Mol Cell Biol 5:1229-1237.

Yenari MA, Giffard RG, Sapolsky RM, Steinberg GK (1999) The neuroprotective potential of heat shock protein 70 (HSP70). Mol Med Today 5:525-531.

Yu Q, Kent CR, Tytell M (2001) Retinal uptake of intravitreally injected $\mathrm{Hsc} / \mathrm{Hsp} 70$ and its effect on susceptibility to light damage. Mol Vis 7:48-56. 